\title{
Electronic and Geometric Structures of Rechargeable Lithium Manganese Sulfate $\mathrm{Li}_{2} \mathrm{Mn}\left(\mathrm{SO}_{4}\right)_{2}$ Cathode
}

\author{
Disha Gupta, ${ }^{\dagger, \nabla}$ Aravind Muthiah, ${ }^{\dagger, \dagger, \nabla}$ Minh Phuong Do, ${ }^{\dagger, \S}$, Gopinathan Sankar, ${ }^{*}, \| \oplus$ \\ Timothy I. Hyde, ${ }^{\perp}$ Mark Patrick Copley, ${ }^{\perp}$ Tom Baikie, ${ }^{,}$Yonghua Du, ${ }^{\# \odot ~ S h i b o ~ X i, ~}{ }^{\#}$ \\ Madhavi Srinivasan, ${ }^{\dagger, \dagger}$ and ZhiLi Dong* ${ }^{*} \dagger \odot$
}

${ }^{\dagger}$ School of Materials Science and Engineering, Nanyang Technological University, 639798 Singapore

‡Energy Research Institute@NTU (ERI@N) Nanyang Technological University Research Techno Plaza, 50 Nanyang Drive, 637553 Singapore

${ }^{\S}$ Interdisciplinary Graduate School, Nanyang Technological University, 50 Nanyang Avenue, 639798 Singapore

"Department of Chemistry, University College London, 20 Gordon Street, London WC1H OAJ, U.K.

${ }^{\perp}$ Johnson Matthey Technology Centre, Blount's Court, Sonning Common, Reading RG4 9NH, U.K.

${ }^{\#}$ Institute of Chemical and Engineering Sciences, A*STAR, 1 Pesek Road, 627833 Singapore

\section{Supporting Information}

ABSTRACT: Here, we report the use of $\mathrm{Li}_{2} \mathrm{Mn}\left(\mathrm{SO}_{4}\right)_{2}$ as a potential energy storage material and describe its route of synthesis and structural characterization over one electrochemical cycle. $\mathrm{Li}_{2} \mathrm{Mn}\left(\mathrm{SO}_{4}\right)_{2}$ is synthesized by ball milling of $\mathrm{MnSO}_{4} \cdot \mathrm{H}_{2} \mathrm{O}$ and $\mathrm{Li}_{2} \mathrm{SO}_{4} \cdot \mathrm{H}_{2} \mathrm{O}$ and characterized using a suite of techniques, in particular, ex situ X-ray diffraction, $\mathrm{X}$-ray photoelectron spectroscopy, and X-ray absorption spectroscopy on the $\mathrm{Mn}$ and S K-edges to investigate the electronic and local geometry around the absorbing atoms. The prepared $\mathrm{Li}_{2} \mathrm{Mn}$ $\left(\mathrm{SO}_{4}\right)_{2}$ electrodes undergo electrochemical cycles to different potential points on the charge-discharge curve and are then extracted from the cells at these points for ex situ structural analysis. Analysis of X-ray absorption spectroscopy (both near

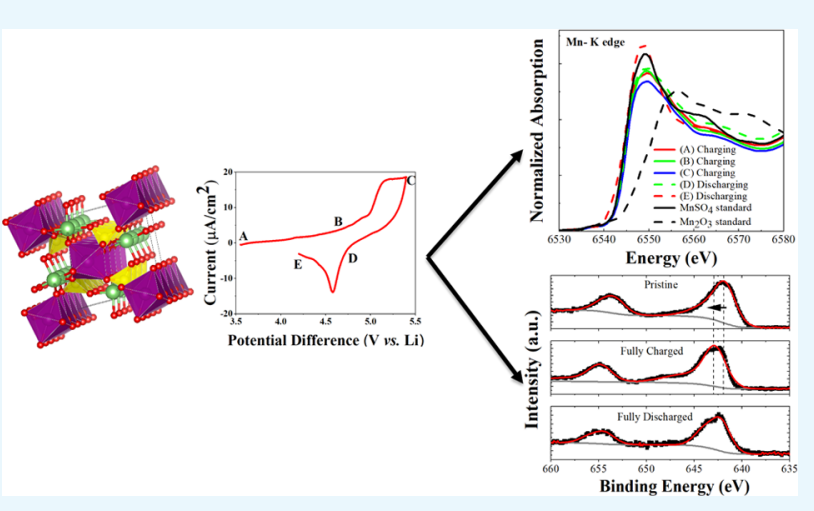
and fine structure part of the data) data suggests that there are minimal changes to the oxidation state of Mn and $S$ ions during charge-discharge cycles. However, X-ray photoelectron spectroscopy analysis suggests that there are changes in the oxidation state of $\mathrm{Mn}$, which appears to be different from the conclusion drawn from X-ray absorption spectroscopy. This difference in results during cycling can thus be attributed to electrochemical reactions being dominant at the surface of the $\mathrm{Li}_{2} \mathrm{Mn}\left(\mathrm{SO}_{4}\right)_{2}$ particles rather than in the bulk.

\section{INTRODUCTION}

Sulfates and fluorosulfates have traditionally demonstrated electrochemical activity only in Fe-based compounds. Among the sulfate-based positive electrode materials, the systems of $\mathrm{Li}_{2} \mathrm{M}\left(\mathrm{SO}_{4}\right)_{2}$ (where $\mathrm{M}=\mathrm{Fe}, \mathrm{Mn}, \mathrm{Co}$ ) synthesized through solid-state reactions have the highest redox potentials for $\mathrm{Fe}$ at $3.83 \mathrm{~V}$ (vs Li), ${ }^{1}$ second only to the ionothermally synthesized fluorosulfate analogue that shows $3.90 \mathrm{~V}$ (vs $\mathrm{Li}$ ). ${ }^{2}$ The high voltages achieved with $\mathrm{Fe}$ systems were attributed to the inductive effect of the highly electronegative sulfate group. ${ }^{3}$ Subsequently, $\mathrm{Co}, \mathrm{Mn}$, and $\mathrm{Ni}$, which traditionally display reversible redox potential at higher voltages, were investigated. $^{4,5}$ The advantage these high-voltage cathodes provide is the possibility of high energy density. For $\mathrm{Li}_{2} \mathrm{M}\left(\mathrm{SO}_{4}\right)_{2}$, the theoretical energy density is $526 \mathrm{Wh} \mathrm{kg}^{-1}$ for Co; $496 \mathrm{Wh} \mathrm{kg}^{-1}$ for $\mathrm{Mn}$; and $400 \mathrm{Wh} \mathrm{kg}^{-1}$ for $\mathrm{Fe}$, if one $\mathrm{Li}$ ion is extracted and $1052 \mathrm{Wh} \mathrm{kg}^{-1}$ for Co; $991 \mathrm{Wh} \mathrm{kg}^{-1}$ for $\mathrm{Mn}$; and $800 \mathrm{Wh} \mathrm{kg}^{-1}$ for $\mathrm{Fe}$, if two $\mathrm{Li}$ ions are extracted. Atomistic modeling/density functional theory techniques predicted the redox potential versus $\mathrm{Li}$ to be $5.2 \mathrm{~V}$ for $\mathrm{Co}$ and $4.54 \mathrm{~V}$ for $\mathrm{Mn}$ systems ${ }^{6}$ and were experimentally backed up by our previous work by Muthiah et al., demonstrating the electrochemical activity at $5.02 \mathrm{~V}$ for $\mathrm{Co}$ and $4.85 \mathrm{~V}$ for $\mathrm{Mn}^{7}$ The lack of performance was largely attributed to the presence of Jahn-Teller distortion $^{8}$ in the case of $\mathrm{Mn}$ (III), and in the case of $\mathrm{Co}$ (II), stable electrolytes operational at high voltages are rare. The most feasible candidate for exploring a high-voltage range with minimal modification to a commercially available electrolyte component is a cosolvent, called sebaconitrile and recent

Received: February 7, 2019

Accepted: May 20, 2019

Published: July 1, 2019 
reports have successfully utilized this electrolyte for manganese and cobalt sulfate electrodes. ${ }^{9-12}$

This work details the structural modifications during the electrochemical process, whereas our previous investigations ${ }^{7}$ primarily concentrated on the full electrochemical analysis of $\mathrm{Li}_{2} \mathrm{Mn}\left(\mathrm{SO}_{4}\right)_{2}$ (LMS), electrolyte selection, effect of particle size distribution, and analysis of X-ray diffraction (XRD) data. We focus on structural analysis in this work to determine electronic and geometric structural changes that take place during the electrochemical process. This necessitates the use of advanced characterization techniques, X-ray absorption spectroscopy (XAS) and X-ray photoelectron spectroscopy (XPS).

$\mathrm{X}$-ray absorption spectroscopy (XAS) is one of the most powerful methods to determine both the electronic and geometric structures, either in situ (during electrochemical operation) or by subjecting the system to specific reaction conditions and investigating the samples by ex situ methods. One of the main advantages of using XAS is that it is elementspecific, which allows the determination of both electronic and geometric structures of the target element of interest within the electrodes. ${ }^{13-16}$ Here, we seek to understand whether the electronic and geometric changes associated with the redox reactions are similar to $\mathrm{Li}_{2} \mathrm{Fe}\left(\mathrm{SO}_{4}\right)_{2}$, where a $\mathrm{Fe}^{2+/ 3+}$ redox couple was observed through XAS analysis. ${ }^{17}$ It is well known that XAS is appropriate for investigating the change in oxidation state and local structure of any type of system as it is element-specific. Therefore, we used ex situ XAS to analyze the electronic and geometric structural changes of the LMS cathode by monitoring the $\mathrm{Mn}$ and $\mathrm{S}$ K-edges during the charge and discharge cycles. In addition to this, XPS analysis was carried out as a complementary technique since they both can access the chemical state of the elements in the surface and near-surface regions, respectively. XPS is a universal tool in surface analysis. By tuning the excitation energy from above $1000 \mathrm{eV}$ down to a few hundred $\mathrm{eV}$ or below, the surface sensitivity can be varied from a few nanometers to below a nanometer. This sensitivity has been used extensively to study the surface composition and chemical state of the reaction layer during its formation.

\section{RESULTS AND DISCUSSION}

2.1. X-ray Diffraction. Figure 1 shows the powder X-ray diffraction (PXRD) pattern of the starting $\mathrm{Li}_{2} \mathrm{Mn}\left(\mathrm{SO}_{4}\right)_{2}$

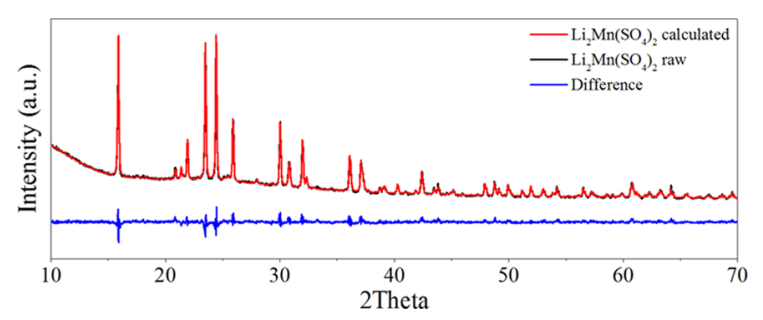

Figure 1. Best fit between calculated XRD data (red), through refinement of using crystallographic data employing TOPAS software, and the measured XRD pattern (black) of the LMS as-prepared material. The difference profile is shown in blue.

(LMS) cathode material. The similarity between the XRD patterns of previously reported $\mathrm{Li}_{2} \mathrm{Co}\left(\mathrm{SO}_{4}\right)_{2}$ and $\mathrm{Li}_{2} \mathrm{Fe}\left(\mathrm{SO}_{4}\right)_{2}$ indicates that $\mathrm{Li}_{2} \mathrm{Mn}\left(\mathrm{SO}_{4}\right)_{2}$ is isostructural with the iron and cobalt compounds. ${ }^{18}$ We also show in Figure 1 the Rietveld refined (using TOPAS software) data using a starting structural model of $\mathrm{Li}_{2} \mathrm{Mn}\left(\mathrm{SO}_{4}\right)_{2}{ }^{1919}$ Rietveld analysis of the LMS starting material gives lattice parameters $a=5.459(5) \AA, b=$ 4.838(5) $\AA, c=8.249(11) \AA, \alpha=\gamma=90^{\circ}$, and $\beta=106.30(10)^{\circ}$ and in the monoclinic spacegroup $P 2_{1} / c$ (no. 14).

Figure 2 shows the structural model of LMS showing the $\mathrm{MnO}_{6}$ and $\mathrm{SO}_{4}$ octahedra and tetrahedra, respectively, and the coordination of the $\mathrm{Li}$ ions between these units. Each $\mathrm{MnO}_{6}$ octahedra is linked to six $\mathrm{SO}_{4}$ tetrahedra via shared oxygen vertices, whereas each $\mathrm{SO}_{4}$ group is linked to only three $\mathrm{MnO}_{6}$ octahedra. The fourth corner of $\mathrm{SO}_{4}$, which is free and not linked to any atom, leads to an open channel where the $\mathrm{Li}$ ions are present.

2.2. Electrochemistry. Figure 3 shows the cyclic voltammetry data of the first cycle illustrating the reversible electrochemical activity of LMS. The cyclic voltammetry data for the other cycles carried out on $\mathrm{Li}_{2} \mathrm{Mn}\left(\mathrm{SO}_{4}\right)_{2}$ are show in the Supporting Information (Figure S2). Oxidation and reduction peaks are observed at 5.17 and $4.57 \mathrm{~V}$ with respect to $\mathrm{Li}$, respectively. The average redox potential of the system was confirmed to be $4.87 \mathrm{~V}$ as per an earlier report by Muthiah et al. $^{7}$ Since the details of the profile are discussed extensively in the work by Muthiah, we only give a brief overview here before analyzing the structural changes that the cathode material undergoes during the charge-discharge cycle.

The open-circuit voltage of the cathode material is $3.5 \mathrm{~V}$ (A) and is chosen as the first state for subsequent ex situ XAS and XPS analyses. This state provides the structure of the cathode material in its pristine state. The second state considered for analysis is at $4.7 \mathrm{~V}(\mathrm{~B})$. This point was chosen as the cycling of the cell is carried out between $4.2 \mathrm{~V}$ (fully discharged) and 5.4 $\mathrm{V}$ (fully charged) and state B lies halfway between these two states. The third state, $C$, chosen is that of the fully charged state at $5.4 \mathrm{~V}$. The fourth state, D, lies at the same voltage of state $\mathrm{B}(4.7 \mathrm{~V})$ but indicates the structural changes during the discharge cycle. The final state analyzed, $\mathrm{E}$, is at $4.2 \mathrm{~V}$ when the cell is fully discharged.

A noticeable feature of the cyclic voltammetry test was current intensity, which is low (in the $\mu \mathrm{A}$ range), indicating that only a part of the cathode material participated in the redox reaction. Ex situ XAS and XPS tests were carried out to shed light on this aspect and on the structural changes of the LMS cathode during cycling.

2.3. X-ray Absorption Spectroscopy (XAS) Analysis. 2.3.1. X-ray Absorption Near-Edge Structure (XANES) Analysis of $M n$ and $S$ K-Edges. To understand the structural changes that occur during the cycling process in the LMS electrodes, various potentials were chosen along the chargedischarge curve (see Figure 3, points $(A-E)$ ) and are listed in Table 1. All of the electrodes underwent the first electrochemical cycle, and the points $(\mathrm{B}-\mathrm{E})$ were electrochemically charged and discharged to the potentials listed in Table 1 . The cells were then disassembled in an Ar-filled glovebox, and the electrodes were extracted for XAS studies. Ex situ XAS studies were then conducted on all of these electrodes at the Mn and S K-edges.

Normalized Mn K-edge XANES data along with Mn(II) and $\mathrm{Mn}$ (III) reference compounds are shown in Figure 4a, and we discuss the pre-edge part of the data first, followed by the changes that are observed in the main absorption edge. The pre-edge for the Mn K-edge pristine sample can be seen to appear at around $6537.9 \mathrm{eV}$, which is commonly assigned to a $1 \mathrm{~s}$ to $3 \mathrm{~d}$ transition, and although it is disallowed by selection rule, it is observed in many transition metal ion-containing 

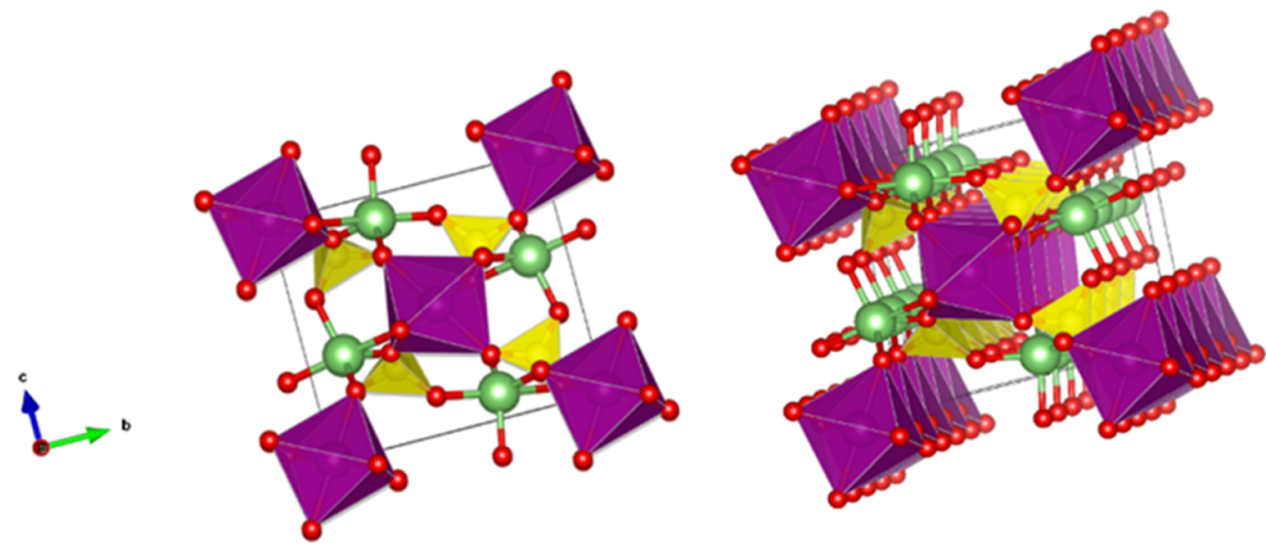

Figure 2. Structure of $\mathrm{LMS}$ where $\mathrm{MnO}_{6}$ is denoted by the purple octahedral and $\mathrm{SO}_{4}$ is indicated by the yellow tetrahedra. Green and red spheres represent the lithium and oxygen ions, respectively.

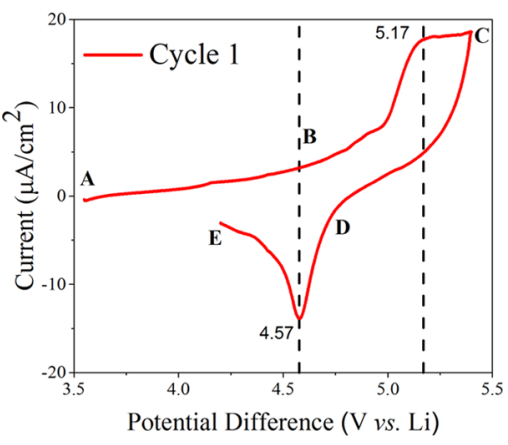

Figure 3. Cyclic voltammetry plot of $\mathrm{Li}_{2} \mathrm{Mn}\left(\mathrm{SO}_{4}\right)_{2}$ (LMS) for the first charge-discharge cycle. Points $(\mathrm{A}-\mathrm{E})$ represent the different cutoff potentials at which the electrodes were stopped during the charging-discharging cycle as shown in Table 1.

Table 1. Different LMS Electrode Details with Their Cutoff Potentials and State of Charge-Discharge

\begin{tabular}{clc} 
electrode & \multicolumn{1}{c}{ charge state } & potential $($ wrt $\mathrm{Li})(\mathrm{V})$ \\
A & pristine electrode, open-circuit voltage & 3.5 \\
B & partial charged & 4.7 \\
C & full charged & 5.4 \\
D & partial discharged & 4.7 \\
E & full discharged & 4.2
\end{tabular}

systems. The reason they appear is a combination of coordination environments and mixing of the $d$ and $p$ orbitals. $^{20,21}$ A negligible change is observed in the pre-edge feature during the charging process (see Figure S3 in the Supporting Information). Also, the pre-edge feature is weak, implying that $\mathrm{Mn}$ is mostly in a octahedral coordination environment. ${ }^{22}$ Furthermore, we do not observe a shift in the absorption edge (which is typically seen if there is a change in oxidation state of the element of interest), suggesting that there is no significant change in the $\mathrm{Mn}(\mathrm{II})$ oxidation state. An attempt was made to analyze the shift using the first derivation of the XANES data. The main inflection point shows a shift of $0.4 \mathrm{eV}$, which is too small to interpret as a change in the oxidation state (see Figure S4 in the Supporting Information). However, we observed changes in the white line intensity of the main absorption (see Figure 4b,c) with charge and discharge, respectively. The white line intensity results from strong transitions to final states confined to the near vicinity of the absorbing atom. In general, for a K-edge spectrum, the systems that have octahedral coordination show the highest intensity, whereas the tetrahedrally coordinated systems show the lowest intensity. ${ }^{23}$ It has been observed that deviation from perfect octahedral coordination can result in a decrease in the white line intensity. Therefore, the decrease in the intensity and broadening of the peak are likely due to an increasing disorder in the system. ${ }^{24}$ Thus, for LMS, we observe a decrease in the white line intensity as the electrode is charged. However, as the electrode undergoes discharge, the white line intensity appears to increase further beyond the pristine sample. This indicates that there is a possibility that the structure of LMS is more ordered in its fully discharged state than it was in the starting material.

The absorption edge for the sulfate K-edge is at approximately $2479 \mathrm{eV}$, which is almost $10 \mathrm{eV}$ higher than that for elemental sulfur, as expected for $S$ in the +6 oxidation state and as anticipated for LMS. The main absorption peak for $\mathrm{S}$ K-edge appears at around $2185.5 \mathrm{eV}$, which corresponds to an $S$ 1s $-t_{2}$ (3p-like) transition. ${ }^{25-29}$ Any peak below that energy corresponds to $1 \mathrm{~s}$ to $3 \mathrm{~s}$ transition, which is forbidden by the selection rules. ${ }^{30}$ Hence, no pre-edge feature was observed for any of the LMS electrodes and $\mathrm{MnSO}_{4}$ standard in the XANES data. As the peak position is similar to that found for the standard material $\mathrm{MnSO}_{4}(2480.2 \mathrm{eV})$, we conclude that the oxidation state for $\mathrm{S}$ is +6 . The main absorption peak and the derivative peak for all of the cycled electrodes overlap each other, as shown in Figure 5a,b, suggesting no change in the oxidation state of sulfur and more importantly that the sulfate structure is stable under the reaction conditions.

The analysis of the main absorption peak in Figure $6 a, b$ shows a change in the white line intensity, and as the electrode is charged, the intensity of the white line decreases, which indicates an increased disorder in the system. However, as the electrode is discharged and returns to its original state, the white line intensity increases and overlaps with that of the starting material. Therefore, a reversible change occurs with one cycle of charge-discharge at the $\mathrm{S}$ K-edge. Table 2 shows the edge energies of both $\mathrm{Mn}$ and $\mathrm{S}$ K-edges of all of the electrodes as determined from the XANES analysis.

2.3.2. Extended X-ray Absorption Fine Structure (EXAFS) Analysis of $M n$ K-Edge. As mentioned earlier, the XANES cannot be analyzed quantitatively; therefore, we use the first shell EXAFS analysis to determine the local structure, in particular, the interatomic distances surrounding the atom of 

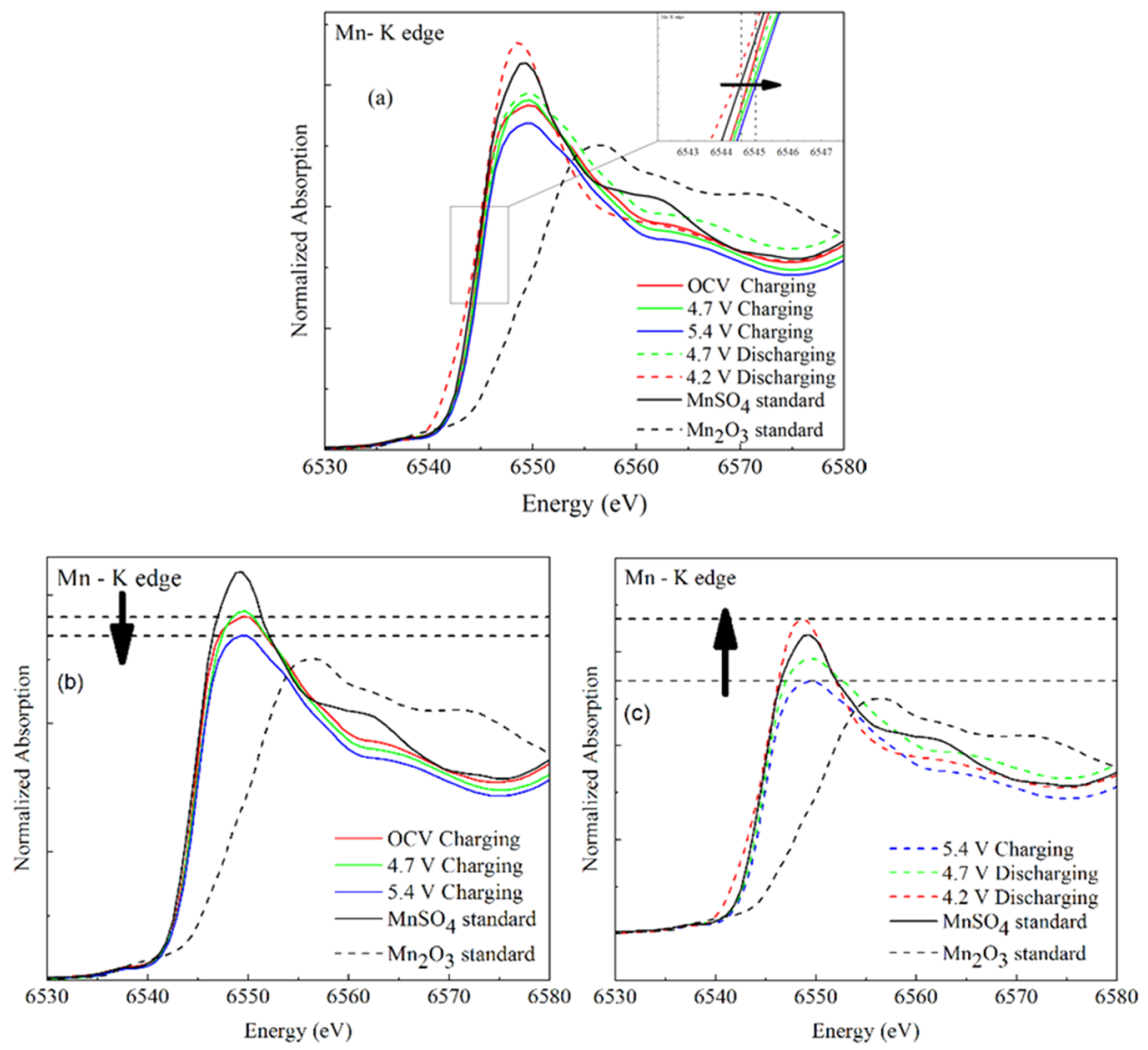

Figure 4. Normalized XANES plots of the main absorption peak of Mn K-edge for LMS electrodes stopped at different potential points (a). The difference in the white line intensity of the normalized XANES plots of the main absorption peak of Mn K-edge for LMS electrodes charged to different potentials (b) and (c). During the charge cycle (b), the white line intensity shifts slightly downward, but for the discharge cycle (c), the intensity increases even beyond that of the starting material.
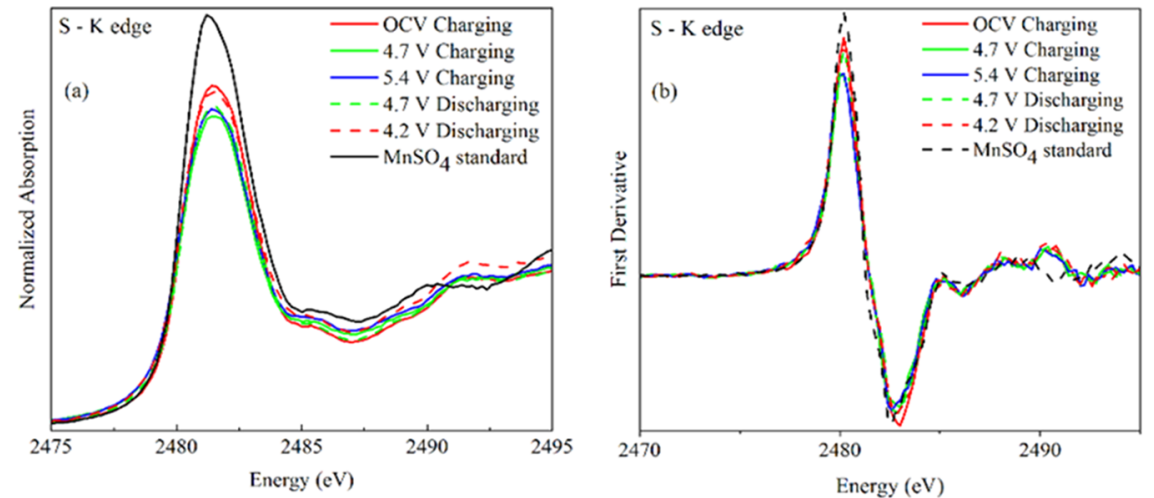

Figure 5. Normalized XANES of the main absorption peak (a) and first-derivative peak (b) is shown for the S K-edge of the LMS electrodes for different points on the cycling curve. No change is observed in the peak positions of sulfur with respect to the standard in comparison, $\mathrm{MnSO}_{4}$ (black dashed), thus proving that all of the sulfur lies at the same oxidation state of +6 throughout the charge-discharge process.

interest. We focused on the first nearest-neighbor analysis as this will be the most sensitive in determining the change in the oxidation state of the manganese ions. The key results obtained from the best fit between calculated and experimental data are listed in Table 3.

As the LMS electrode was charged from its pristine state at $3.5 \mathrm{~V}$ to fully charged state at $5.4 \mathrm{~V}$, a very slight variation in the $\mathrm{Mn}-\mathrm{O}$ bond length is observed. The average $\mathrm{Mn}-\mathrm{O}$ bond distance for the starting material is found to be $2.12 \AA$, and with one full electrochemical cycle, the $\mathrm{Mn}-\mathrm{O}$ bond for the fully discharged electrode is found to be $2.09 \AA$. It is observed that the change in $\mathrm{Mn}-\mathrm{O}$ distances of all of the various treated samples falls between 2.09 and $2.12 \AA$, which is very close and supports the XANES observation that there is little to no change in the oxidation of $\mathrm{Mn}$ in the bulk of the compound. The Debye-Waller factor $\left(\sigma^{2}\right)$ for all of the LMS electrodes are found to be in the range of $0.003-0.007 \AA^{2}$. This is mainly due to the nature of the fitting procedure we employed, wherein we used the average $\mathrm{Mn}-\mathrm{O}$ distance over six neighbors. The crystal structure data suggests that there are four $\mathrm{Mn}-\mathrm{O}$ distances of ca. $2.11 \AA$ and two $\mathrm{Mn}-\mathrm{O}$ distances of ca. $2.22 \AA$. As our data range is between 3.2 and $9.8 \AA$ (the estimated resolution in the bond distance for this data range is $0.12 \AA$ ), we conducted our analysis using one single average bond distance. Therefore, one would expect a slightly higher Debye-Waller factor representing the static disorder. The best 

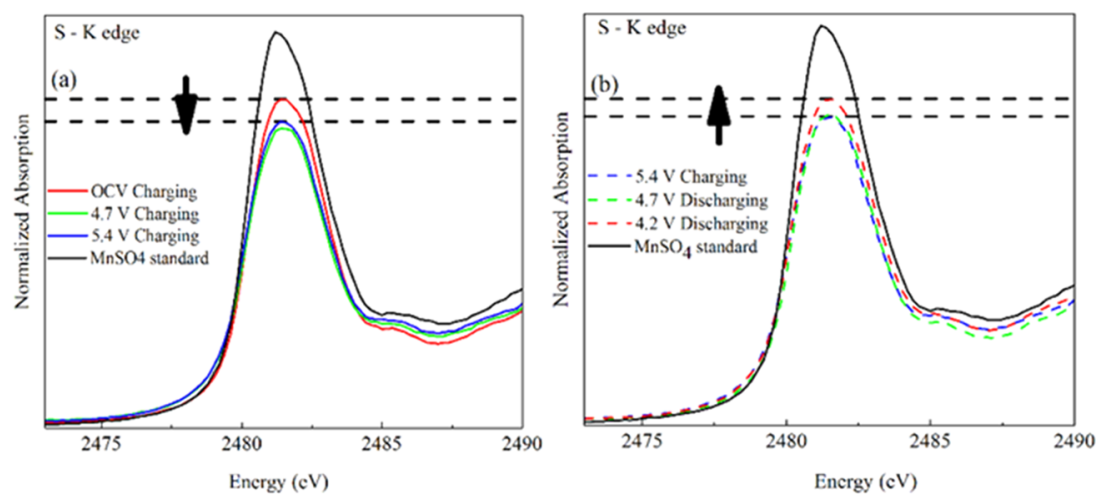

Figure 6. Normalized XANES plots of the main absorption peak of S K-edge for LMS electrodes for different potential cutoff points are shown during charge (a) and discharge (b). For the charge cycle, we see that the white line intensity decreases in (a), whereas during discharge (b), the intensity again increases back to its original position.

Table 2. Edge Energies for Mn and S K-Edges, Obtained from the First-Derivative Peak Positions, Are Tabulated for All of the LMS Electrodes at the Different Cutoff Potentials during the Electrochemical Cycle

\begin{tabular}{clccc} 
& & & \multicolumn{2}{c}{ edge energy } \\
\cline { 3 - 5 } electrode & \multicolumn{1}{c}{ charge state } & potential $($ wrt Li) $(\mathrm{V})$ & Mn K-edge (eV) & S K-edge (eV) \\
A & pristine electrode, open-circuit voltage & 3.5 & 6544.85 & 2480.20 \\
B & partial charged & 4.7 & 6544.91 & 2480.11 \\
C & full charged & 5.4 & 6545.01 & 2480.09 \\
D & partial discharged & 4.7 & 6544.95 & 2480.19 \\
E & full discharged & 4.2 & 6544.88 & 2480.17
\end{tabular}

Table 3. EXAFS Data Obtained after Fourier Transform Analysis of Mn K-Edge for LMS Electrodes at Different Potential Points on the Cycling Curve ${ }^{a, b}$

$\begin{array}{cllccccc}\text { electrode } & \text { charge state } & \text { bond } & \text { CN } & \sigma^{2} & R & R \text {-factor } & \text { BVS } \\ \text { A } & \text { pristine } & \mathrm{Mn}-\mathrm{O} & 6 & 0.003(0.003) & 2.12(0.036) & 0.03 & 2.486 \\ \text { B } & \text { partial charged } & \mathrm{Mn}-\mathrm{O} & 6 & 0.005(0.004) & 2.12(0.052) & 0.01 & \\ \text { C } & \text { fully charged } & \mathrm{Mn}-\mathrm{O} & 6 & 0.007(0.005) & 2.09(0.066) & 0.01 & 2.323 \\ \text { D } & \text { partial discharged } & \mathrm{Mn}-\mathrm{O} & 6 & 0.004(0.004) & 2.10(0.057) & 0.02 & \\ \text { E } & \text { fully discharged } & \mathrm{Mn}-\mathrm{O} & 6 & 0.007(0.004) & 2.11(0.055) & 0.02 & 2.492\end{array}$

${ }^{a} \mathrm{CN}$, coordination number; $\sigma^{2}$, EXAFS Debye-Waller factor or disorder factor; $R$, bond distance obtained after Fourier transform fitting; $R$-factor, goodness of fit. ${ }^{b}$ Bond valence sum is given by $\mathrm{BVS}_{i}{ }^{31}=\sum_{j=1}^{\mathrm{n}} \exp \left[\left(R_{0}-R\right) / B\right]$, where $i$ is the binding site $(\mathrm{Mn}), R_{0}$ is the empirically determined constant; for $\mathrm{Mn}(\mathrm{II})-\mathrm{O}, R_{0}=1.79$ and for $\mathrm{Mn}(\mathrm{III})-\mathrm{O}, R_{0}=1.76,{ }^{32} \mathrm{~B}=0.37,{ }^{31}$ an empirically determined constant, and $n$ is coordination number of binding site $i$.

match between experimental and calculated Fourier transform of the Mn K-edge data is shown in Figure S5 of the Supporting Information.

2.4. XPS Analysis of Mn $2 p$ and S $2 p$. The Mn $2 p$ XPS data in Figure 7 and two main peaks between the binding energies of 640 and $660 \mathrm{eV}$ were observed and assigned to $\mathrm{Mn}$ $\left(2 \mathrm{p}_{1 / 2}\right)$ and $\mathrm{Mn}\left(2 \mathrm{p}_{3 / 2}\right)$, respectively. The individual binding energies are listed in Table 4.

The main trend observed is an increase of the binding energy across all peaks as the system is charged, indicating the presence of a higher oxidation state. ${ }^{33}$ Further evidence of change in the oxidation state can be seen through the appearance of satellite peaks at 658.8 and $646.6 \mathrm{eV}$. An earlier report on $\mathrm{MnO}$ oxidation ${ }^{34}$ shows the formation of a similar satellite peak upon an increased exposure of $\mathrm{MnO}$ to $\mathrm{O}_{2}$ at 673 $\mathrm{K}$. This was attributed to the layered growth of $\mathrm{Mn}_{2} \mathrm{O}_{3}$, and therefore, the XPS spectra was distinguished as a characteristic of $\mathrm{Mn}$ in its $3+$ oxidation state. Upon discharge, the satellite peaks of both $\mathrm{Mn}\left(2 \mathrm{p}_{1 / 2}\right)$ and $\mathrm{Mn}\left(2 \mathrm{p}_{3 / 2}\right)$ disappeared, indicating the conversion of $\mathrm{Mn}(\mathrm{III})$ to $\mathrm{Mn}(\mathrm{II})$, although a complete reversal of the main peak binding energy to the original value of the pristine electrode is not seen. This indicates that some percentage of $\mathrm{Li}$ involved in the oxidation reaction has not participated in the reduction reaction, thereby leading to some irreversible capacity loss. ${ }^{33}$

The $S 2 p$ spectra are critical to evaluate as it is likely that the polyanionic part of the LMS compound could participate in the electrochemistry of the battery and thereby cause changes in the capacity or voltage. Figure 8 shows the $S 2$ p spectra of all of the three states of the sample. The binding energies of all of the three states of charge are almost identical, although a marginal shift of the spectra of the fully charged electrode toward a higher binding energy is observed. Nevertheless, after complete discharge, the spectrum of the fully discharged electrode overlaps with that of the pristine electrode, indicating that this reaction is reversible.

While the Mn K-edge XAS data suggest that there is no noticeable change in the oxidation state of $\mathrm{Mn}(\mathrm{II})$, a change in current is observed from the cyclic voltammetry curve. However, the observed current during the charging process is fairly low (in $\mu \mathrm{A}$ ), indicating that only a small part of the $\mathrm{Mn}$ (II) undergoes a redox reaction. XPS indeed supports the 


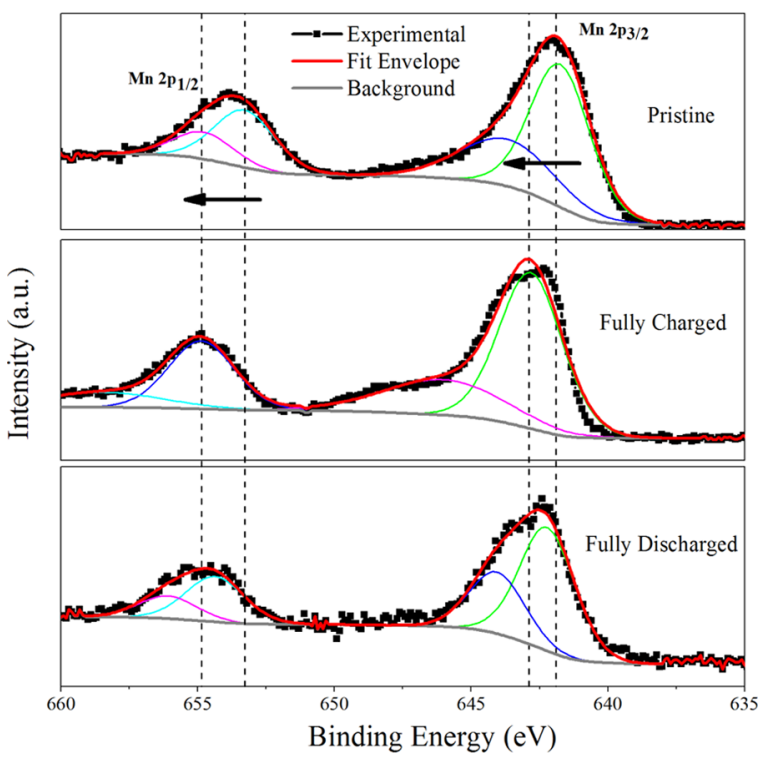

Figure 7. Manganese Mn 2p ex situ XPS spectra of pristine, charged, and discharged states of LMS electrodes.

Table 4. Binding Energies of Main Peaks of Mn 2p XPS Spectra for Three Different Electrodes

\begin{tabular}{lccccc} 
& & \multicolumn{4}{c}{ binding energy of $\mathrm{Mn}(\mathrm{eV})$} \\
\cline { 3 - 6 } electrode & state of charge & $\begin{array}{c}2 \mathrm{p}_{1 / 2} \\
\text { satellite }\end{array}$ & $\begin{array}{c}2 \mathrm{p}_{1 / 2} \\
\text { main }\end{array}$ & $\begin{array}{c}2 \mathrm{p}_{3 / 2} \\
\text { satellite }\end{array}$ & $\begin{array}{c}2 \mathrm{p}_{3 / 2} \\
\text { main }\end{array}$ \\
\hline pristine & $\begin{array}{c}\text { uncharged at } \\
3.5 \mathrm{~V}\end{array}$ & 654.8 & 653.3 & 643.7 & 641.7 \\
charge & $\begin{array}{c}\text { fully charged to } \\
5.4 \mathrm{~V}\end{array}$ & 658.8 & 654.8 & 646.6 & 642.87 \\
discharge & $\begin{array}{c}\text { fully discharged to } \\
4.2 \mathrm{~V}\end{array}$ & 656.1 & 654.4 & 644.1 & 642.1 \\
& & & & & \\
\hline
\end{tabular}

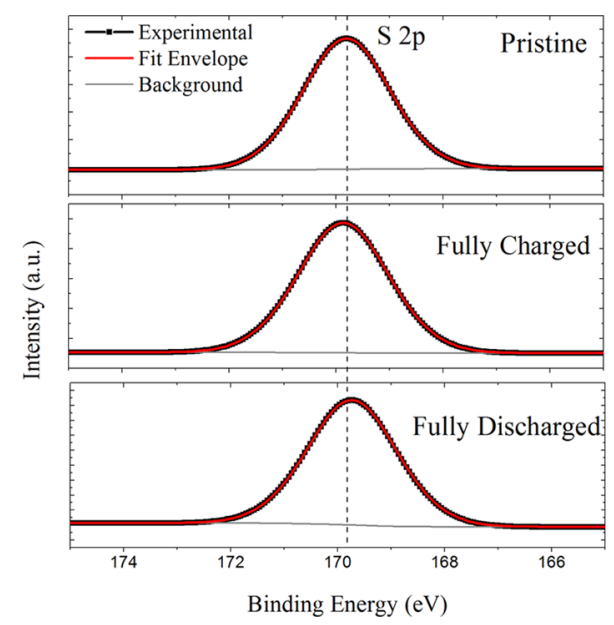

Figure 8. Sulfur S 2p ex situ XPS spectra of pristine, charged, and discharged states of LMS electrodes.

finding as the changes seen in Mn 2p XPS are possibly related to the $\mathrm{Mn}$ (II) ions present on the surface of the electrode material, whereas the bulk remains unaltered.

\section{EXPERIMENTAL METHODS}

3.1. Synthesis. 3.1.1. LMS Material Synthesis. For the synthesis of $\mathrm{LMS}, \mathrm{MnSO}_{4}$ anhydrous and $\mathrm{Li}_{2} \mathrm{SO}_{4}$ (5\% excess) were used as precursors. Anhydrous $\mathrm{MnSO}_{4}$ and $\mathrm{Li}_{2} \mathrm{SO}_{4}$ were prepared by heating $\mathrm{MnSO}_{4} \cdot \mathrm{H}_{2} \mathrm{O}$ and $\mathrm{Li}_{2} \mathrm{SO}_{4} \cdot \mathrm{H}_{2} \mathrm{O}$ (SigmaAldrich) in a tube furnace under an argon gas flow for approximately $1 \mathrm{~h} . \mathrm{MnSO}_{4} \cdot \mathrm{H}_{2} \mathrm{O}$ was treated at $300{ }^{\circ} \mathrm{C}$ and $\mathrm{Li}_{2} \mathrm{SO}_{4} \cdot \mathrm{H}_{2} \mathrm{O}$ at $200{ }^{\circ} \mathrm{C}$. The anhydrous powders were then mixed in a ratio of $1.3: 1$ by weight, respectively, and ball-milled in a SPEX 8000M high-energy ball mill for $30 \mathrm{~min}$ in a stainless steel vial. The resulting powder was pressed into a pellet of 20 $\mathrm{mm}$ diameter using a pelletizer at a pressure of $8 \mathrm{MPa}$. The pellet was then annealed in a box furnace for $12 \mathrm{~h}$ at $500{ }^{\circ} \mathrm{C}$ with a temperature ramp of $5{ }^{\circ} \mathrm{C} \mathrm{min}^{-1}$. After annealing, the pellet was ground, pelletized, and annealed under the same conditions. Finally, the pellet was ground to a fine powder before carrying out the structural analysis. The powder was stored in an Ar-filled glovebox to prevent moisture absorption as the material is sensitive to degradation by moisture.

3.1.2. Electrode Preparation. For the preparation of the electrode, the LMS powder was mixed with Super P carbon in the ratio of 80:20 (powder/carbon) and dried under vacuum in a Buchi oven for $2 \mathrm{~h}$. The dried mixture was then placed in a tungsten carbide vial and ball-milled in a SPEX 8000D Mixer/ Mill high-energy ball mill for $20 \mathrm{~h}$, with $10 \mathrm{~min}$ of cooling after each hour of milling. The milling was done in a tungsten carbide vial to avoid $\mathrm{Ni}$ contamination, which would otherwise occur in the case of a stainless steel vial. The ball-milled powder was then dried at $250^{\circ} \mathrm{C}$ in a Buchi oven for another 4 $\mathrm{h}$ before storing inside an Ar-filled glovebox.

3.1.3. Electrolyte Preparation. The electrolyte used for the cell assembly of these electrodes can be synthesized using $\mathrm{LiPF}_{6}$. A $1 \mathrm{M}$ solution of $\mathrm{LiPF}_{6}$ was prepared with a solvent of ethylene carbonate/dimethyl carbonate/sebaconitrile (15:15:70 by volume). The solution was stirred overnight inside an argon-filled glovebox.

3.1.4. Cell Assembly. The powder was tested as a cathode material in a half-cell configuration using a coin cell $(20 \mathrm{~mm} x$ $1.6 \mathrm{~mm})$. The LMS powder was placed directly over the positive case as the working cathode. Lithium foil was used as the counter and reference electrode. The loading of the active material was $4 \mathrm{mg} \mathrm{cm}^{-2}$. Two pieces of porous glass microfiber (Whatman cat. no. 1825-047, U.K.) were used as the separator and soaked in the electrolyte solution $(200 \mu \mathrm{L})$.

3.2. Material Characterization. 3.2.1. Electrochemical Characterization. 3.2.1.1. Cyclic Voltammetry. Cyclic voltammetry tests using Solartron Analytical were carried out over three cycles at a scan rate of $0.05 \mathrm{mV} \mathrm{s}^{-1}$ between a range of 4.2 and $5.4 \mathrm{~V}$ for LMS.

3.2.2. Structural Characterization. 3.2.2.1. Powder X-ray Diffraction. Sample purity was established using powder X-ray diffraction (PXRD) from patterns collected with a Bruker D8 diffractometer (Bragg-Brentan geometry) equipped with $\mathrm{Cu}$ $\mathrm{K} \alpha$ radiation, which operated at $40 \mathrm{kV}$ and $40 \mathrm{~mA}$. The asprepared sample was mounted in a top-loaded sample holder, and data were collected at $2 \theta$ from 10 to $80^{\circ}$ using a step size of $0.02^{\circ}$. Rietveld refinement of the XRD data was carried out with TOPAS V4.1 (Bruker, 2008) using the fundamental parameter approach. ${ }^{35}$

3.2.2.2. X-ray Absorption Spectroscopy (XAS). The samples for XAS measurements were prepared by charging (or discharging) the electrode in a coin cell setup to different voltages followed by disassembly in the argon-filled glovebox. The electrode was then scraped off in the powder form, sealed, and afterward transferred to an XAS sample holder. The polypropylene tape-sealed electrodes and the representative manganese oxide and sulfate standards were measured at the 
X-ray absorption fine structure facility focused on catalysis research (XAFCA) beamline ${ }^{36}$ of the Singapore Synchrotron Light Source. The X-ray energy was calibrated at the inflection point of the absorption edges of manganese and sulfur elemental standards for $\mathrm{Mn}$ and $\mathrm{S}$ K-edges, respectively. All XAS measurements were collected at a ring energy of ca. 0.7 $\mathrm{GeV}$ and a ring current of ca. $200 \mathrm{~mA}$. A Si(111) crystal monochromator was used, and data were collected for both $\mathrm{Mn}$ and S K-edges at ambient temperature and pressure. For Mn K-edge, the data were collected on XAFCA in Quick EXAFS transmission mode in the range between 6418 and $7088 \mathrm{eV}$ and a typical scan time of $180 \mathrm{~s}$. Multiple scans were collected and averaged to improve the data quality and signalto-noise ratio. For $S$ K-edge, the data were collected in fluorescence mode with a silicon drift detector in the energy range between 2392 and $2551 \mathrm{eV}$ with a scan time of $20 \mathrm{~min}$ per scan and three scans were collected and averaged to improve the quality of data. XAS data of reference compounds $\left(\mathrm{MnSO}_{4}, \mathrm{Mn}_{2} \mathrm{O}_{3}\right)$ were collected using ca. $5 \mathrm{mg}$ of respective powders mixed with ca. $60 \mathrm{mg}$ of boron nitride and pressed into a $10 \mathrm{~mm}$ diameter pellet, which was mounted onto the sample holder for XAS measurements in either transmission (Mn K-edge) or fluorescence (S K-edge) mode. The Mn and S K-edge X-ray absorption near-edge structure (XANES) and extended X-ray absorption fine structure (EXAFS) data were analyzed using Athena and Artemis software included in the Demeter package for XAS analysis. ${ }^{37,38} \mathrm{Mn}$ K-edge XAS data was fitted in the $k$ range between 3.16 and $9.5 \AA^{-1}$ and $r$ range between 1.5 and $3.4 \AA$ with $k$ weights of 1,2 , and 3 .

3.2.2.3. X-ray Photoelectron Spectroscopy (XPS). For the XPS measurements, the electrode was scraped off in the powder form and then transferred to the XPS chamber with minimal exposure to air. XPS experiments were carried out using a PHI5802 Multitechnique spectrometer, and each spectrum was collected after $1 \mathrm{~min}$ of $\mathrm{Ar}^{+}$sputtering. XPS analysis of the system was carried out similar to the XAS measurements on three electrodes of different states of charge: (i) pristine uncharged, (ii) fully charged, and (iii) fully discharged. The measurements were carried out for five elements: (i) Mn 2p, (ii) Li 1s, (iii) S 2p, (iv) O 1s, and (v) C $1 \mathrm{~s}$, where the $\mathrm{C}$ served for baseline correction.

\section{CONCLUSIONS}

In this work, $\mathrm{Li}_{2} \mathrm{Mn}\left(\mathrm{SO}_{4}\right)_{2}$ (LMS) was successfully synthesized and electrochemically tested in a lithium half-cell to demonstrate the average redox potential at $4.87 \mathrm{~V}$ vs $\mathrm{Li}$, which is the highest voltage observed for a Mn-based cathode material. A detailed study of the redox process of this highvoltage, Mn-based cathode material was carried out through ex situ XAS and XPS techniques. Analysis of the XANES and EXAFS data reveals that the oxidation state of $\mathrm{Mn}$ ions remained to be $2+$ through the electrochemical reaction. The $S$ K-edge shows no change in the oxidation state during cycling, implying that the sulfate ions are stable under the reaction conditions. XPS studies reveal that the redox couple of $\mathrm{Mn}^{2+/ 3+}$ is present; however, this technique is sensitive to the ions present near the surface of the material, whereas XAS provides information of the entire bulk of the sample. The results are consistent with the observation in the current density seen in the electrochemical study wherein only micro-ampere increase is observed during the charging cycle. Therefore, we conclude that only the $\mathrm{Mn}$ (II) ions present on the surface of the electrode particles are oxidized to $\mathrm{Mn}$ (III) ions and contribute to the electrochemistry, whereas the bulk of the material does not participate in the electrochemical reaction. Nanosizing of the LMS cathode material through novel synthesis techniques would aid in increasing the surface area of the cathode and thereby improve its performance, making it viable for commercial use.

\section{ASSOCIATED CONTENT}

\section{S Supporting Information}

The Supporting Information is available free of charge on the ACS Publications website at DOI: 10.1021/acsomega.9b00356.

Electrolyte stability test for high-voltage applications; cyclic voltammetry plots of $\mathrm{Li}_{2} \mathrm{Mn}\left(\mathrm{SO}_{4}\right)_{2}$; pre-edge and first-derivative XANES of Mn K-edge; EXAFS fittings of the Mn K-edge at different cutoff potentials; and oxygen O 1s ex situ XPS spectra of pristine, charged, and discharged states (PDF)

\section{AUTHOR INFORMATION}

\section{Corresponding Authors}

*Email: g.sankar@ucl.ac.uk (G.S.).

*E-mail: ZLDong@ntu.edu.sg (Z.D.).

\section{ORCID}

Minh Phuong Do: 0000-0001-9009-9080

Gopinathan Sankar: 0000-0001-5152-3424

Yonghua Du: 0000-0003-2655-045X

ZhiLi Dong: 0000-0001-8116-6747

\section{Author Contributions}

$\nabla$ D.G. and A.M. contributed equally to this work.

Notes

The authors declare no competing financial interest.

\section{ACKNOWLEDGMENTS}

We would like to thank Singapore Synchrotron Light Source for access to the XAFCA beamline that contributed to the results presented here and Johnson Matthey and Nanyang Technological University for their financial support.

\section{REFERENCES}

(1) Reynaud, M.; Ati, M.; Melot, B. C.; Sougrati, M. T.; Rousse, G.; Chotard, J.-N.; Tarascon, J.-M. $\mathrm{Li}_{2} \mathrm{Fe}\left(\mathrm{SO}_{4}\right)_{2}$ as a 3.83 V Positive Electrode Material. Electrochem. Commun. 2012, 21, 77-80.

(2) Barpanda, P.; Ati, M.; Melot, B. C.; Rousse, G.; Chotard, J. N.; Doublet, M. L.; Sougrati, M. T.; Corr, S. A.; Jumas, J. C.; Tarascon, J. M. A $3.90 \mathrm{~V}$ iron-based fluorosulfate material for lithium-ion batteries crystallizing in the triplite structure. Nat. Mater. 2011, 10, 772-779.

(3) Gutierrez, A.; Benedek, N. A.; Manthiram, A. Crystal-Chemical Guide for Understanding Redox Energy Variations of $\mathrm{M}^{2+} /{ }^{3+}$ Couples in Polyanion Cathodes for Lithium-Ion Batteries. Chem. Mater. 2013, 25, 4010-4016.

(4) Reynaud, M.; Ati, M.; Boulineau, S.; Sougrati, M. T.; Melot, B. C.; Rousse, G.; Chotard, J.-N.; Tarascon, J.-M. Bimetallic Sulfates $\mathrm{A}_{2} \mathrm{M}\left(\mathrm{SO}_{4}\right)_{2} \cdot \mathrm{nH}_{2} \mathrm{O}(\mathrm{A}=\mathrm{Li}, \mathrm{Na}$ and $\mathrm{M}=$ transition metal $)$ : As New Attractive Electrode Materials for $\mathrm{Li}$-and Na-ion Batteries. ECS Trans. 2013, 50, 11-19.

(5) Reynaud, M.; Rousse, G.; Chotard, J.-N.; Rodríguez-Carvajal, J.; Tarascon, J.-M. Marinite $\mathrm{Li}_{2} \mathrm{M}\left(\mathrm{SO}_{4}\right)_{2}(\mathrm{M}=\mathrm{Co}, \mathrm{Fe}, \mathrm{Mn})$ and $\mathrm{Li}_{1} \mathrm{Fe}\left(\mathrm{SO}_{4}\right)_{2}$ : Model Compounds for Super-Super-Exchange Magnetic Interactions. Inorg. Chem. 2013 52, 10456-10466.

(6) Clark, J. M.; Eames, C.; Reynaud, M.; Rousse, G.; Chotard, J. N.; Tarascon, J. M.; Islam, M. S. High voltage sulfate cathodes $\operatorname{Li} 2 \mathrm{M}(\mathrm{SO} 4)(2)(\mathrm{M}=\mathrm{Fe}, \mathrm{Mn}, \mathrm{Co})$ : atomic-scale studies of lithium 
diffusion, surfaces and voltage trends. J. Mater. Chem. A 2014, 2, $7446-7453$.

(7) Muthiah, A.; Baikie, T.; Ulaganathan, M.; Copley, M.; Yang, G.; Aravindan, V.; Srinivasan, M. Structural, Thermal, and Electrochemical Studies of Novel Li2CoxMn1-x(SO4)(2) Bimetallic Sulfates. J. Phys. Chem. C 2017, 121, 24971-24978.

(8) Rousse, G.; Tarascon, J. M. Sulfate-Based Polyanionic Compounds for Li-Ion Batteries: Synthesis, Crystal Chemistry, and Electrochemistry Aspects. Chem. Mater. 2014, 26, 394-406.

(9) Nagahama, M.; Hasegawa, N.; Okada, S. High Voltage Performances of Li2NiPO4F Cathode with Dinitrile-Based Electrolytes. J. Electrochem. Soc. 2010, 157, A748-A752.

(10) Guerfi, A.; Trottier, J.; Gagnon, C.; Liu, D.; Hovington, P.; Zaghib, K.; Mauger, A.; Groult, H.; Julien, C. M. Reactivity of Electrolyte with the Surface of 5-volts Positive Electrode Materials for Li-ion Batteries. ECS Trans. 2014, 58, 41-46.

(11) Xu, W.; Hu, J. Z.; Engelhard, M. H.; Towne, S. A.; Hardy, J. S.; Xiao, J.; Feng, J.; Hu, M. Y.; Zhang, J.; Ding, F.; Gross, M. E.; Zhang, J. G. The stability of organic solvents and carbon electrode in nonaqueous Li-O-2 batteries. J. Power Sources 2012, 215, 240-247.

(12) Nanini-Maury, E.; Swiatowska, J.; Chagnes, A.; Zanna, S.; Pierre, T. V.; Marcus, P.; Cassir, M. Electrochemical behavior of sebaconitrile as a cosolvent in the formulation of electrolytes at high potentials for lithium-ion batteries. Electrochim. Acta 2014, 115, 223233.

(13) Yu, X. Q.; Lyu, Y. C.; Gu, L.; Wu, H. M.; Bak, S. M.; Zhou, Y. N.; Amine, K.; Ehrlich, S. N.; Li, H.; Nam, K. W.; Yang, X. Q. Understanding the Rate Capability of High-Energy-Density Li-Rich Layered $\mathrm{Li}_{1.2} \mathrm{Ni}_{0.15} \mathrm{Co}_{0.1} \mathrm{Mn}_{0.55} \mathrm{O}_{2}$ Cathode Materials. Adv. Energy Mater. 2014, 4, No. 1300950.

(14) Tsai, Y. W.; Hwang, B. J.; Ceder, G.; Sheu, H. S.; Liu, D. G.; Lee, J. F. In situ X-ray absorption spectroscopic study on variation of electronic transitions and local structure of $\mathrm{LiNi} 1 / 3 \mathrm{Co} 1 / 3 \mathrm{Mn} 1 / 3 \mathrm{O} 2$ cathode material during electrochemical cycling. Chem. Mater. 2005, 17, 3191-3199.

(15) Deb, A.; Bergmann, U.; Cramer, S. P.; Cairns, E. J. In situ x-ray absorption spectroscopic study of the $\mathrm{Li}[\mathrm{Nil} / 3 \mathrm{Col} / 3 \mathrm{Mn} 1 / 3] \mathrm{O}-2$ cathode material. J. Appl. Phys. 2005, 97, No. 113523.

(16) Lyu, Y. C.; Zhao, N. J.; Hu, E. Y.; Xiao, R. J.; Yu, X. Q.; Gu, L.; Yang, X. Q.; Li, H. Probing Reversible Multielectron Transfer and Structure Evolution of Li1.2Cr0.4Mn0.4O2 Cathode Material for LiIon Batteries in a Voltage Range of 1.0-4.8 V. Chem. Mater. 2015, 27, $5238-5252$

(17) Muthiah, A.; Baikie, T.; Shukla, S.; Ball, S.; Copley, M.; Hyde, T. I.; Du, Y.; Sankar, G.; Aravindan, V.; Srinivasan, M. Ex situ XAS investigation of effect of binders on electrochemical performance of Li2Fe(SO4) 2 cathode. J. Mater. Chem. A 2017, 5, 19963-19971.

(18) Reynaud, M.; Ati, M.; Melot, B. C.; Sougrati, M. T.; Rousse, G.; Chotard, J. N.; Tarascon, J. M. $\mathrm{Li} 2 \mathrm{Fe}(\mathrm{SO} 4)(2)$ as a $3.83 \mathrm{~V}$ positive electrode material. Electrochem. Commun. 2012, 21, 77-80.

(19) Reynaud, M.; Rousse, G.; Chotard, J. N.; Rodriguez-Carvajal, J.; Tarascon, J. M. Marinite $\operatorname{Li2M}(\mathrm{SO} 4)(2)(\mathrm{M}=\mathrm{Co}, \mathrm{Fe}, \mathrm{Mn})$ and Li1Fe(SO4)(2): Model Compounds for Super-Super-Exchange Magnetic Interactions. Inorg. Chem. 2013, 52, 10456-10466.

(20) Yamamoto, T. Assignment of pre-edge peaks in K-edge x-ray absorption spectra of $3 \mathrm{~d}$ transition metal compounds: electric dipole or quadrupole? X-Ray Spectrom. 2008, 37, 572-584.

(21) Vanderlaan, G.; Kirkman, I. W. The 2p Absorption-Spectra of 3d Transition-Metal Compounds in Tetrahedral and Octahedral Symmetry. J. Phys.: Condens. Matter 1992, 4, 4189-4204.

(22) Figueroa, S. J. A.; Requejo, F. G.; Lede, E. J.; Lamaita, L.; Peluso, M. A.; Sambeth, J. E. XANES study of electronic and structural nature of $\mathrm{Mn}$-sites in manganese oxides with catalytic properties. Catal. Today 2005, 107-108, 849-855.

(23) Henderson, G. S.; de Groot, F. M. F.; Moulton, B. J. A. X-ray Absorption Near-Edge Structure (XANES) Spectroscopy. In Spectroscopic Methods in Mineralogy and Materials Sciences; Mineralogical Society of America, 2014; Vol. 78, p 75.
(24) Schnohr, C. S.; Ridgway, M. C. Introduction to X-Ray Absorption Spectroscopy. In X-ray Absorption Spectroscopy of Semiconductors; Springer-Verlag: Berlin, Heidelberg, 2015.

(25) Okude, N.; Nagoshi, M.; Noro, H.; Baba, Y.; Yamamoto, H.; Sasaki, T. A. P and S K-edge XANES of transition-metal phosphates and sulfates. J. Electron Spectrosc. Relat. Phenom. 1999, 101-103, 607610.

(26) Zhu, M. Q.; Northrup, P.; Shi, C. Y.; Billinge, S. J. L.; Sparks, D. L.; Waychunas, G. A. Structure of Sulfate Adsorption Complexes on Ferrihydrite. Environ. Sci. Technol. Lett. 2014, 1, 97-101.

(27) Zhu, M. Q. Molecular Structure of Sulfate Adsorption Complexes on Ferrihydrite: Impacts of $\mathrm{Ph}$, Ionic Strength, and Wetness. In Abstracts of Papers of the American Chemical Society; American Chemical Society: Washington, DC, 2014; Vol. 247.

(28) Prietzel, J.; Thieme, J.; Herre, A.; Salome, M.; Eichert, D. Differentiation between adsorbed and precipitated sulfate in soils and at micro-sites of soil aggregates by sulfur K-edge XANES. Eur. J. Soil Sci. 2008, 59, 730-743.

(29) Pingitore, N. E.; Meitzner, G.; Love, K. M. Identification of Sulfate in Natural Carbonates by X-Ray-Absorption Spectroscopy. Geochim. Cosmochim. Acta 1995, 59, 2477-2483.

(30) Li, D.; Bancroft, G. M.; Kasrai, M.; Fleet, M. E.; Feng, X. H.; Tan, K. S-K-Edge and L-Edge X-Ray-Absorption Spectroscopy of Metal Sulfides and Sulfates-Applications in Mineralogy and Geochemistry. Can. Mineral. 1995, 33, 949-960.

(31) Brown, I. D.; Altermatt, D. Bond-Valence Parameters Obtained from a Systematic Analysis of the Inorganic Crystal-Structure Database. Acta Crystallogr., Sect. B: Struct. Sci. 1985, 41, 244-247.

(32) Thorp, H. H. Bond Valence Sum Analysis of Metal-Ligand Bond Lengths in Metalloenzymes and Model Complexes. Inorg. Chem. 1992, 31, 1585-1588.

(33) Zhang, R.; Yu, X.; Nam, K.-W.; Ling, C.; Arthur, T. S.; Song, W.; Knapp, A. M.; Ehrlich, S. N.; Yang, X.-Q.; Matsui, M. $\alpha$-MnO 2 as a cathode material for rechargeable $\mathrm{Mg}$ batteries. Electrochem. Commun. 2012, 23, 110-113.

(34) Di Castro, V.; Polzonetti, G. XPS study of MnO oxidation. J. Electron Spectrosc. Relat. Phenom. 1989, 48, 117-123.

(35) Cheary, R. W.; Coelho, A. A Fundamental Parameters Approach to X-Ray Line-Profile Fitting. J. Appl. Crystallogr. 1992, $25,109-121$.

(36) Du, Y. H.; Zhu, Y.; Xi, S. B.; Yang, P.; Moser, H. O.; Breese, M. B. H.; Borgna, A. XAFCA: a new XAFS beamline for catalysis research. J. Synchrotron Radiat. 2015, 22, 839-843.

(37) Ravel, B.; Newville, M. ATHENA and ARTEMIS: Interactive graphical data analysis using IFEFFIT. Phys. Scr. 2005, T115, 10071010

(38) Ravel, B.; Newville, M. ATHENA, ARTEMIS, HEPHAESTUS: data analysis for X-ray absorption spectroscopy using IFEFFIT. J. Synchrotron Radiat. 2005, 12, 537-541. 